\title{
Early and late complications after endoscopic sphincterotomy for biliary lithiasis with and without the gall bladder 'in situ'
}

\author{
J ESCOURROU, J A CORDOVA, F LAZORTHES, J FREXINOS, \\ AND A RIBET \\ From the Clinique des Maladies de l'Appareil Digestif, CHU de Rangueil, Toulouse, France
}

SUMMARY Endoscopic sphincterotomy has gained wide acceptance in the treatment of biliary lithiasis. We attempted endoscopic sphincterotomy in 443 patients and were successful in 407 (92\%). Sphincterotomy was carried out with the gall bladder in situ in 234 cases $(57 \%)$ of advanced age or high surgical risk. Immediate complications occurred in $7 \%$, of which haemorrhage was the most frequent. The mortality rate was $1.5 \%$. Three hundred and sixteen endoscopic sphincterotomies were performed more than six months before writing and follow up was available for $226(72 \%)$ from six to 78 months. Late complications were observed in 16 patients with gall bladder 'in situ' $(12 \%)$; the most frequent was cholecystitis in $6 \%$. In five patients of the group without gall bladder, four had cholangitis related to retained or recurrent stones, and one restenosed. No episodes of cholangitis were observed in patients without stones despite reflux of barium up the biliary tree as observed during a barium meal examination.

Endoscopic sphincterotomy is one of the most important advances in the treatment of common bile duct stones. This technique has gained wide acceptance since Classen, Demling, and Kawai ${ }^{12}$ performed the first successful procedure in 1974.

Several publications describe the technique and its immediate complications ${ }^{3-9}$ but few give information on long term results. ${ }^{10} 11$

The aim of the present investigation was to evaluate the nature and frequency of long term complications particularly the incidence of acute cholecystitis and reflux cholangitis, which are indications for cholecystectomy and could question the appropriateness of the endoscopic sphincterotomy technique.

\section{Methods}

PATIENTS

In all cases endoscopic sphincterotomy was performed with an 'Olympus' duodenoscope JFB2, JFB3 or JF1T and the Demling and Classen sphincterotome.

Address for correspondence: Dr Jean Escourrou. Service des Maladies de l'Appareil Digestif. CHU de Rangueil. 31054 Toulouse. Cedex. France. Received for publication 29 July 1983
Common bile duct clearance after sphincterotomy was ascertained by methods which distinguish two different periods.

Until February 1979 assessment of biliary tract clearance was obtained by recovery of stones in the faeces. If the stones were not found a second visualisation of the common bile duct was carried out either by endoscopic retrograde cholangiopancreatography (ERCP) (29 cases) or by retrograde choledochoscopy with a paediatric endoscope (16 cases).

After February 1979, the opened common bile duct was checked by reopacification during the course of the initial procedure and when necessary, clearance attempted with the aid of a balloon catheter or a Dormia basket. When clearance of the common bile duct was in doubt because of difficulties in radiographic interpretation or persistent indications of cholestasis (21 patients), a new investigation was undertaken a few days later: six by endoscopic retrograde cholangiopancreatography, nine by retrograde choledochoscopy with a paediatric endoscope, and six with the prototype Olympus Babyscope.

Long term results were evaluated in all cases on the basis of recurrent symptoms and laboratory evidence of cholestasis during out patient follow up 
or by a questionnaire sent to the patients and to the referring physician. In the event of complications, a new endoscopic retrograde cholangiopancreatography was performed. Six months after sphincterotomy 60 asymptomatic patients underwent a barium meal examination to look for signs of biliary reflux. In all of these cases a plain film of the abdomen was obtained to look for air in the bile ducts. Thirty patients were submitted to intravenous cholangiograms to assess whether this could provide adequate visualisation of the biliary tree and to avoid repeating the endoscopic retrograde cholangiopancreatography.

\section{Results}

Endoscopic sphincterotomy was attempted in 443 patients from December 1975. The procedure was successful in 407 subjects $(92 \%)$. Indications for successful sphincterotomy were: 234 patients with choledocholithiasis with gall bladder 'in situ' (Group I) due to advanced age and/or high surgical risk and 173 patients with choledocholithiasis after cholecystectomy (Group II) as shown in Table 1. Twenty six patients from Group II still had a $T$ tube drain in place when endoscopic sphincterotomy was performed. The mean age was 79 years for patients in Group I, all of whom had one or more serious concomitant medical problems including cardiorespiratory, neurovascular, or renal insufficiency. The mean age for Group II was 66 years. The male to female ratio was $1: 2$ in both groups.

Immediate complications occurred in 27 patients (7\%) with six deaths (1.5\%) (Table 2). These included severe haemorrhage (more than three units of blood), perforation and pancreatitis. In $71 \%$ of
Table 2 Immediate complications of endoscopic sphincterotomy in 407 patients

\begin{tabular}{llll}
\hline Complication & Patients (no) & $\begin{array}{l}\text { Urgent operation } \\
\text { required }\end{array}$ & Deaths \\
\hline Haemorrhage & 18 & 2 & 2 \\
Perforation & 6 & 3 & 2 \\
Pancreatitis & 3 & 2 & 2 \\
& $27(7 \%)$ & $7(1.7 \%)$ & $6(1.5 \%)$ \\
\hline
\end{tabular}

the sphincterotomies achieved by February 1979, the calculi passed spontaneously into the duodenum and were recovered in the faeces (Table 1). Among the 45 patients in whom this did not occur endoscopic extraction was successful in 39 . For the remaining six patients, clearance of the common bile duct was unsuccessful owing to impaction of the stones.

The 254 sphincterotomies performed after February 1979 included an immediate attempt at stone extraction. Clearance of the common bile duct was established during the procedure in 233 cases. Among the 21 patients who underwent secondary investigations, one had spontaneous clearance of the biliary tract, 11 had active stone extractions, and, for the remaining nine, extraction failed because the stones were too large to be removed. Of the total of 15 patients in both groups in whom the stones could not be removed, eight came to surgery, and seven who were considered too old were given medical therapy instead.

Out of 407 successful endoscopic sphincterotomies, 316 were performed more than six months ago and of these detailed follow up information was available on 226 (72\%).

Table 1 Indications and confirmation of biliary tract clearance

\begin{tabular}{|c|c|c|c|c|}
\hline & \multirow[b]{2}{*}{ Gall bladder in situ } & \multicolumn{2}{|c|}{ After cholecystectomy } & \multirow[b]{2}{*}{ Total \% } \\
\hline & & No $T$-tube & $T$-tube 'in situ' & \\
\hline & \multicolumn{4}{|c|}{ Up to Feb 1979: 170 sphincterotomies } \\
\hline Number of attempts & 102 & 57 & 11 & 170 \\
\hline Successful sphincterotomy & 92 & 51 & 10 & $153(90 \%)$ \\
\hline Stones in faeces & 56 & 42 & 10 & $108(71 \%)$ \\
\hline Early recheck: 45 & & & & \\
\hline secondary extraction & 31 & 8 & - & $39(25 \%)$ \\
\hline \multirow[t]{2}{*}{ extraction failure } & 5 & 1 & - & $6(4 \%)$ \\
\hline & \multicolumn{4}{|c|}{ After Feb 1979: 273 sphincterotomies } \\
\hline Number of attempts & 153 & 103 & 17 & 273 \\
\hline Successful sphincterotomy & 142 & 96 & 16 & $254(93 \%)$ \\
\hline $\begin{array}{l}\text { Immediate extraction (balloon + basket) } \\
\text { Early recheck: } 21\end{array}$ & 128 & 89 & 16 & $\begin{array}{r}233(92 \%) \\
21(8.2 \%)\end{array}$ \\
\hline secondary extraction & 6 & 5 & - & $11(4.3 \%)$ \\
\hline extraction failure & 7 & 2 & - & $9(3.5 \%)$ \\
\hline free biliary tract & 1 & - & - & $1(0.4 \%)$ \\
\hline
\end{tabular}


Information was not available on the others as neither the patients nor the referring physician responded to our questionnaire. In those with gall bladder 'in situ' (175), 130 were reviewed or answered the questionnaire $(74 \%)$ with follow up of six to 66 months (mean 22 months) (Table 3). Late complications occurred in 16 cases $(12 \%)$ : eight presented with acute cholecystitis one to nine months after endoscopic sphincterotomy (mean four months), seven patients were treated by cholecystectomy, one received medical treatment; there was no mortality, nor were there any late sequelae.

In five other patients with cholangitis related to retained or recurrent stones, three were operated on one to nine months after the original endoscopic sphincterotomy after a further failure of endoscopic stone extraction; the other two were treated again by endoscopic sphincterotomy and stone extraction was performed with the help of a basket catheter. Two patients restenosed four and 12 months after endoscopic sphincterotomy: both were treated again by endoscopy and are now free of biliary symptoms. The remaining patient developed a gall bladder cancer four years after endoscopic sphincterotomy (Table 4).

In the group of patients with choledocholithiasis after cholecystectomy (141), 96 were reviewed six months to five years later $(68 \%$, Table 3$)$; late complications were observed in five $(5.2 \%)$; three with retained or recurrent stones underwent surgery, two, 10 and 11 months after endoscopic sphincterotomy. One patient had an intrahepatic stone. The last patient developed a stenosis from the sphincterotomy after 21 months; a new sphincterotomy was performed with good results which lasted for three months. The patient then developed a further restenosis and was consequently treated surgically. This patient was operated on yet again two months later for a duodenal stenosis probably related to a pancreatic carcinoma (Table 4 ).

There were 28 late deaths (six months to five years
Table 3 Follow up after endoscopic sphincterotomy

\begin{tabular}{lll}
\hline & Patients (no) & $\%$ \\
\hline Group l: Gallbladder in situ & & \\
6-12 months & 43 & 33 \\
1-3 years & 61 & 47 \\
3-6.5 years & 26 & 20 \\
Group II: After cholecystectomy & & \\
6-12 months & 45 & 47 \\
1-3 years & 32 & 33 \\
3-6.5 years & 19 & 20 \\
\hline
\end{tabular}

after endoscopic sphincterotomy). In all cases, patients were free of biliary symptoms and death was related to cardiovascular or neurological diseases.

Barium studies showed evidence of biliary reflux in $65 \%$ of the patients. Plain films of the abdomen revealed air in the biliary tract in $70 \%$. Intravenous cholangiograms were performed in 30 patients, but in 17 cases we found false calculi images forcing us to abandon this method.

\section{Discussion}

Endoscopic sphincterotomy now constitutes another option in the treatment of choledocholithiasis. This technique has numerous advantages which explains its wide acceptance: absence of general anaesthesia and laparotomy, with the consequent reduction of hospital stay and costs. The overall success rate is between $86 \%$ and $96 \% .^{+12-15}$ Endoscopic sphincterotomy is considered successful if common bile duct clearance is obtained spontaneously or with the help of a basket or balloon catheter.

Immediate complications are reported in several publications and are very closely related to ours. ${ }^{+8} 15$ The percentage of complications is relatively low if it is considered that endoscopic sphincterotomy is carried out in patients who have been submitted to biliary surgery (cholecystectomy)

Table 4 Late complications of endoscopic sphincterotomy in 226 patients (follow up six to 78 months)

\begin{tabular}{|c|c|c|c|c|c|}
\hline & \multirow[b]{2}{*}{ Patients (no) } & \multirow[b]{2}{*}{ Complications (no) } & \multirow[b]{2}{*}{$\%$} & \multicolumn{2}{|c|}{ Treatment } \\
\hline & & & & Surgery & Endoscopy \\
\hline Gall bladder in situ & 130 & 16 & $12 \cdot 3$ & 11 & 5 \\
\hline Cholecystitis & & 8 & $6 \cdot 2$ & 7 & 0 \\
\hline Cholangitis & & 5 & $3 \cdot 8$ & 3 & 2 \\
\hline Restenosis & & 2 & $1 \cdot 5$ & 0 & 2 \\
\hline Gall bladder cancer & & 1 & 0.7 & 1 & () \\
\hline After cholecystectomy & 96 & 5 & $5 \cdot 2$ & 4 & 1 \\
\hline Cholangitis & & 4 & $4 \cdot 1$ & 3 & 1 \\
\hline Restenosis & & 1 & 1 & 1 & 0 \\
\hline
\end{tabular}


or in older patients with a high operative risk. Mortality increases after 65 years of age and the incidence of complications after surgical choledochotomy can be as high as $30 \% .^{16-18}$ The comparison of mortality attributed to endoscopic sphincterotomy which varies from 0.2 to $1.5 \% 4681114$ with that of surgical sphincterotomy, which varies between 2.9 and $4.4 \%$ (where most of the problems relate to severe pancreatitis, rare after endoscopic sphincterotomy) ${ }^{1-23}$ would suggest that endoscopic sphincterotomy is the procedure of choice for this group of patients.

Long term studies have shown that $87 \%$ of patients with gall bladder 'in situ' showed good functional results. From these patients only $6.2 \%$ developed one or more incidents of acute cholecystitis needing cholecystectomy. These results show that it is not necessary to perform cholecystectomy routinely. In addition, if a cholecystectomy does become necessary, previous endoscopic sphincterotomy does not make the procedure any more difficult technically and may avoid the additional risks related to a choledochotomy. The incidence of cholecystitis after endoscopic sphincterotomy is as low as $1-5 \%$ in other publications. ${ }^{1324} 25$

In patients with or without a gall bladder, the frequency of cholangitis after endoscopic sphincterotomy was $4 \%$. In these cases further investigation always showed the presence of recurrent or retained stones. Despite the reflux shown on barium studies, we never observed clinical symptoms related to reflux. In addition, each time we observed cholangitis this resolved after stone extraction. Long term complications after surgical sphincterotomy have been attributed to reflux but our results suggest that retained or recurrent stones are a more important factor. It is possible that the two could coexist, but that before the days of retrograde endoscopic studies, the stones escaped detection.

Restenosis after endoscopic sphincterotomy is a rare complication and can easily be treated by a new endoscopic sphincterotomy with excellent prospects for success. As far as can be concluded from a follow up of $72 \%$, gall bladder complications after endoscopic sphincterotomy are rare even when gall stones remain, Cholecystectomy is required only if cholecystitis occurs. Duodenal biliary reflux is seen frequently on barium studies, but is never related to cholangitis. Cholangitis is always associated with stenosis or the presence of bile duct stones.

Endoscopic sphincterotomy is now a valuable alternative management for patients with choledocholithiasis who have a high operative risk, and it also offers a good complementary treatment to patients with retained stones after surgery.
We would like to thank Dr S G Bown for help with the preparation of this manuscript in English.

\section{References}

1 Classen M, Demling L. Endoskopische sphincterotomie der papilla vateri und steinextraktion aus ductus choledochus. Dtsh Med Wochenschr 1974; 99: 496-7.

2 Kawai K, Akasaka Y, Murakami K, Tada M, Nakajima M. Endoscopic sphincterotomy of the ampulla of Vater. Gastrointest Endosc 1974; 20: 148-51.

3 Cotton PB. Non operative removal of bile duct stones by duodenoscopic sphincterotomy. Br J Surg 1980; 67: $1-5$.

4 Cotton PB, Vallon AG. British experience with duodenoscopic sphincterotomy for removal of bile duct stones. Br J Surg 1981; 68: 373-5.

5 Cremer M, Gulbis A, Toussaint J, De Toeuf J, Van Laethem A, Hermanus A. La sphincterotomie endoscopique. Contribution belge à l'experience mondiale. Acta Gastroenterol Belg 1977; 40: 41-54.

6 Geenen JE, Vennes JA, Silvis SE. Resumé of a Seminar on endoscopic retrograde sphincterotomy (ERS). Gastrointest Endosc 1981; 27: 31-7.

7 Koch K, Rosch W, Schaffner O, Demling L. Endoscopic papillotomy. Gastroenterology 1977; 73: 1393-6.

8 Neuhaus B, Safrany L. Complications of endoscopic sphincterotomy and their treatment. Endoscopy 1981; 13: 197-9.

9 Reiter J, Bayer H, Mennicken C, Manegold C. Results of endoscopic papillotomy: a collective experience from nine endoscopic centers in West Germany. World J Surg 1978; 2: 505-11.

10 Classen M, Burmeister W, Hagenmuller F, Wurbs D. Long term examination after endoscopic papillotomy. Gastrointest Endosc 1979; 25: 37.

11 Rosch W, Riemann JF, Lux G, Lindner HG. Longterm follow-up after endoscopic sphincterotomy. Endoscopy 1981; 18: 152-3.

12 Anonymous. Endoscopic sphincterotomy. [Editorial] Lancet 1981; 8244: 453-5.

13 Liguory C, Coffin JC, Chiche B, Leger L. Sphincterotomies oddiennes endoscopiques. Nouv Press Med 1979; 8: 403-8.

14 Nakajima M, Kizu M, Akasaka Y, Kawai K. Five years experience of endoscopic sphincterotomy in Japan. A collective study of 25 centers. Endoscopy 1979; 2: 138-41.

15 Viceconte G, Viceconte GW, Pietropaolo V, Montori A. Endoscopic sphincterotomy: indications and results. Br J Surg 1981; 68: 376-80.

16 Glenn F. Trends in surgical treatment of calculous disease of the biliary tract. Surg Gynecol Obstet 1975; 140: $877-84$. 
17 Kakos GS, Tompkins RK, Turnipseed W. Operative cholangiography during routine cholecystectomy. A review of 3012 cases. Arch Surg 1972; 104: 484-8.

18 Vellacott KD, Powell PH. Exploration of the common bile duct, a comparative study. Br J Surg 1979; 66: 389-91.

19 Bismuth H, Hepp J. Indications de la sphincterotomie dans le traitement de la lithiase biliaire. Nouv Press Med 1976; 5: 2949-51.

20 Chigot JP. Le risque opératoire dans la lithiase biliaire. A propos de 5433 interventions. Sem Hôp Paris 1981; 57: 1311-9.

21 Goinard P, Pelissier G. Dix huit ans de chirurgie des lithiases cholédociennes sans drainage biliaire externe.
Bilan de la sphinctérotomie. Chirurgie 1975; 101: 650-61.

22 Hivet M, Richarme J, Chevrel JP, Berlinsky M. 340 sphincterotomies oddiennes. Technique, indications, résultats immédiats et tardifs. Ann Chir 1967; 21: 1409-13.

23 Safrany L. Endoscopic treatment of biliary tract diseases. An international study. Lancet 1978; 2: 983-5.

24 Classen M, Ossenberg F, Schreider H. Papillotomy and biliodigestive anastomosis. Clin Gastroenterol 1979; 2: 506-24.

25 Escourrou J. La sphinctérotomie endoscopique a-t-elle une place importante dans le traitement de la lithiase biliaire? Gastroentérol Clin Biol 1983; 7: 113-6. 